\title{
Ultrasonic Studies of Solid Azobenzene-Decorated Polymer Thin Films
}

\author{
Mohammed Moniruzzaman,* Paraskevi Christogianni, Ranko M. Vrcelj, ${ }^{\circledR}$ and Philip P. Gill` \\ Centre for Defence Chemistry, Cranfield University, Defence Academy of the United Kingdom, Shrivenham SN6 8LA, U.K.
}

Supporting Information

ABSTRACT: This work investigates the effect of ultrasound on switching of cis azobenzene isomers to their trans counterparts in solid films of methyl methacrylate and methacryloyloxyazobenzene copolymers [P(MMA/MOAB $)]$. Ultraviolet-visible and ${ }^{1} \mathrm{H}$ nuclear magnetic resonance spectroscopies demonstrate that $46 \%$ of the cis isomer converts to the trans form purely by ultrasonic agitation and $46 \%$ converts to the trans isomer by localized ultrasoundinduced heating effects. Comparative studies of isomerization by ultrasound wave, heat, and visible irradiation show that ultrasound exposure requires a longer time to switch the cisto-trans conformation. The estimated activation energy for the cis-to-trans conversion in solid polymer films is shown to be comparable to previous values of azobenzene isomerization, indicating that incorporation of the chromophore in a polymeric system affects the kinetics of transition but not the barriers to conformational change.

\section{INTRODUCTION}

It is now well-established that stimuli-responsive molecules can change their molecular shape under appropriate stimuli such as light, temperature, $\mathrm{pH}$, and mechanical force, allowing the control of physical, optical, and even mechanical properties of the host materials. ${ }^{1,2}$ The use of mechanical energy to trigger molecules into different forms is of great interest because of the possible applications in optical switching and data storage, liquid crystal displays, molecular machines, surface relief gratings, nanodevices, and nonlinear optics. ${ }^{3-10}$

One group of such materials are the azobenzene $(A B)$-based chromophores, which can reversibly alter their isomeric forms between trans (planar, t-AB) and cis (twisted, c-AB) geometries in response to external stimuli such as light and heat. ${ }^{11-15}$ In glassy polymers such as methacrylic polymers, isomerization occurs through the inversion of the azo $(-\mathrm{N}=$ $\mathrm{N}-$ ) bond because this mechanism requires a smaller free volume than rotation. ${ }^{16}$ In the case of $\mathrm{AB}$-based polymers, the distance between the two benzene rings of the $A B$ chromophore is altered reversibly by $39 \%$ from 9 to 5.5 $\AA,{ }^{17,18}$ resulting in associated changes in the mechanical properties of a polymer matrix (Figure 1). Previous investigations of a $10 \%$ mol AB-loaded methacrylic polymer film exposed to ultraviolet (UV) light demonstrated an increase of stiffness by $19 \%$ through photo-induced reorganization of polymer chains during isomerization. ${ }^{19}$

Ultrasonic treatment has been shown to affect the interconversion of $\mathrm{AB}$ molecules in solution, where Surampudi et al. $^{20}$ reported the ultrasound-induced isomerization of a methyl acrylate polymer solution containing $A B$ in the main
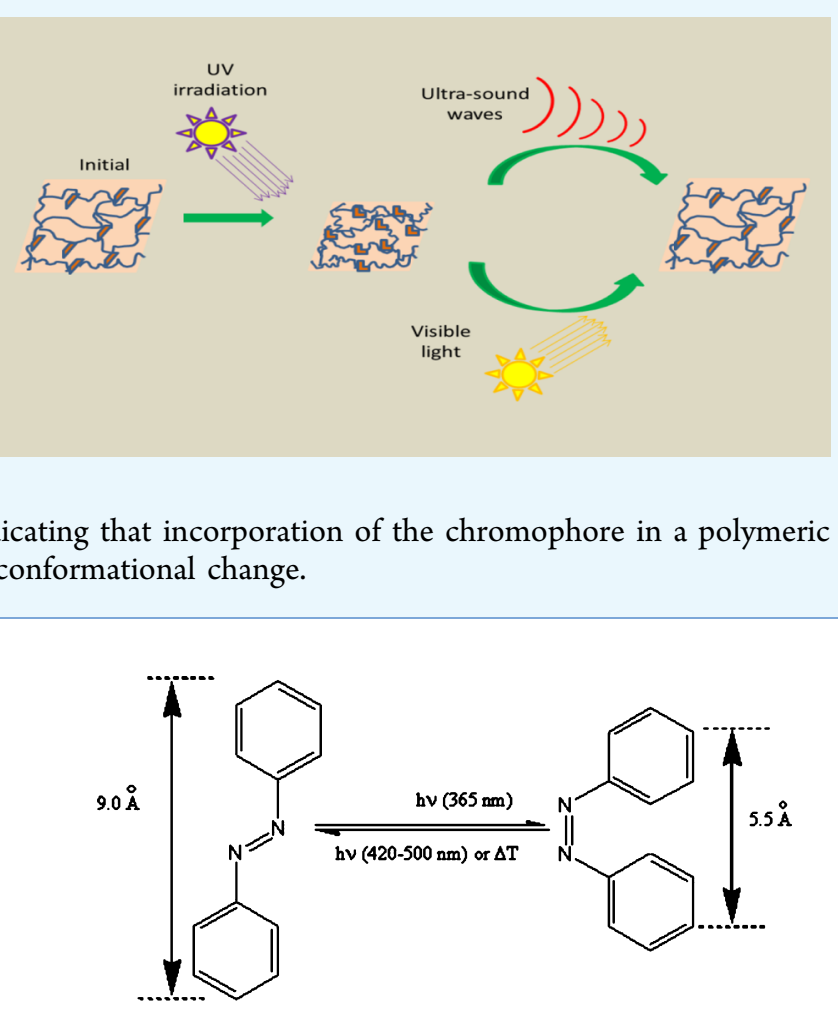

Figure 1. Reversible isomerization of $\mathrm{AB}$ molecule.

chain. This pivotal work underpins the study here. However, for everyday usage of these types of materials, for example, in opto-mechanical devices ${ }^{21,22}$ and solar thermal energy storage, $^{23}$ these materials need to be in a solid form; thus it is important to identify the nature of the cis $\rightarrow$ trans $(\mathrm{c}-\mathrm{AB} \rightarrow$ $\mathrm{t}-\mathrm{AB}$ ) isomerization by ultrasound in solid polymers rather than in liquid.

Analogous to light irradiation, ultrasound will lead to rise in temperature of a solid or solution of $\mathrm{AB}$ polymers. Changes in temperature during light and ultrasonic treatment of $A B$-based materials do not affect the quantum yield of trans $\rightarrow$ cis $(t-A B$ $\rightarrow \mathrm{c}-\mathrm{AB})$ isomerization; but the quantum yield decreases significantly for the $c-A B \rightarrow t-A B$ isomerization. ${ }^{15}$ Thus, the measurement of ultrasound-induced temperature rises in the

Received: August 15, 2018

Accepted: November 20, 2018

Published: December 19, 2018 
AB-based polymer films and their associated isomerization are of great importance in this type of investigation.

In this paper, we report the effect of sonication on the switching of $A B$ isomers (c- $A B$ to $t-A B)$ in polymer thin films. The thermal and ultrasound-induced contribution to the isomerization modes have been separated and reported. The activation energy barrier associated with the cis-to-trans isomerization is also discussed.

\section{MATERIALS AND METHODS}

2.1. Materials. Azobisisobutyronitrile (AIBN, 98\% SigmaAldrich) and triethylamine (99.99\% Sigma-Aldrich) were used without further purification. Methyl methacrylate (MMA, 99\%), 4-phenylazophenol (98\%), methacryloyl chloride (97\%), ethanol (99.9\%), and tetrahydrofuran, (THF; 99.9\%) were supplied by Alfa Aesar and used as received.

The synthesis of $\mathrm{AB}$ polymers is described elsewhere. ${ }^{9,24} \mathrm{~A}$ typical synthetic scheme is shown in Figure 2.

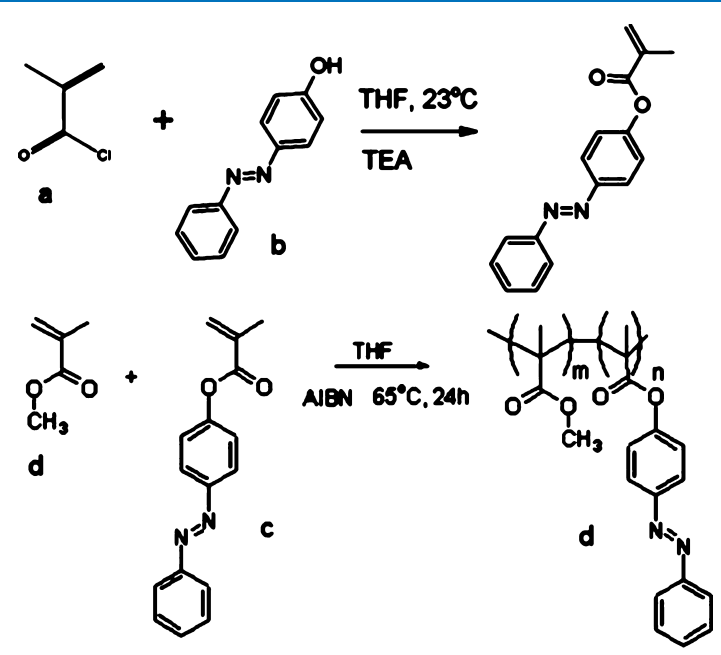

Figure 2. Polymerization scheme for the $A B$ polymers.

4-Phenylazophenol was functionalized to a methacryloyloxyazobenzene (MOAB) monomer by reacting methacryloyl chloride in the presence of triethylamine (soft base). A series of copolymers of MMA and MOAB monomers with varying $\mathrm{AB}$ loadings were prepared. The monomers were polymerized to polymethyl methacrylate and polymethacryloyloxyazobenzene $[\mathrm{P}(\mathrm{MMA} / \mathrm{MOAB})]$ at $65{ }^{\circ} \mathrm{C}$ in $\mathrm{THF}$ using $3 \% \mathrm{~mol}$ AIBN as the free-radical initiator. The reaction mixture was degassed by freeze thaw cycles prior to polymerization. After $48 \mathrm{~h}$ of polymerization, the polymer was precipitated by adding ethanol. Subsequently, the precipitate was dissolved in toluene and reprecipitated by adding ethanol to remove lower molecular weight polymers, and the final polymer was then dried under vacuum. The precursors, monomer, and polymer structures were characterized by nuclear magnetic resonance (NMR) spectroscopy, as seen below, and the molecular mass of the polymer was determined by gel permeation chromatography (GPC).

2.2. Thin Film Preparation. Films were cast by dispersing $5 \% \mathrm{w} / \mathrm{v}$ toluene solution of the polymer $(1 \mathrm{~mL})$ onto microscope glass slides placed onto a level glass table. The solvent was allowed to evaporate slowly at room temperature for $24 \mathrm{~h}$. The resultant films were transferred into a vacuum oven where the residual solvent was removed by continuous pumping for 3 days at room temperature. Complete dryness of the films was confirmed by periodically monitoring the mass of a film until a constant mass was reached, and thin films of 7-9 $\mu \mathrm{m}$ deep were created.

2.3. Structure Modification. Polymer modification was performed by ultrasound, heat, and irradiation methods.

2.3.1. Sonication and Structural Changes Analysis. PMMA, P(MMA/MOAB), and PMOAB films were held in black plastic bags (solid thin films) and held in a thermostatically controlled aqueous ultrasonic bath (Grant $400 \mathrm{~W}$ ) operating at $50-60 \mathrm{kHz}$ at room temperature, $25,30,40$, and $50{ }^{\circ} \mathrm{C}$. Solutions of the polymers for ${ }^{1} \mathrm{H}$ NMR analysis were held in NMR tubes under the same conditions.

2.3.2. Heat Treatment of Films. Heat treatment of the polymer systems was performed using the same bath as the sonication studies but with no ultrasound applied.

2.3.3. Irradiation of Thin Films. Isomerization was performed with a xenon lamp (Zeiss, BLX 500/4). The films were irradiated at room temperature with a $5 \mathrm{~mm}$-diameter light guide using a Novacure M2100 light source (EXFO Photonic Solutions Inc.). Filters of wavelength range of 290320 and 400-500 $\mathrm{nm}$ were employed for obtaining UV and visible light exposure, respectively. The intensity of light was $1000 \mathrm{~mW} \mathrm{~cm}^{-2}$ for UV and visible irradiation. Apart from illuminating sources, the experimental area was kept in darkness.

2.3.4. Storage. Films were stored in black plastic bags and within a black container when not in use or when being subjected to ultrasound.

2.4. Characterization. 2.4.1. Monitoring of Temperature. Thermal measurements of the ultrasound processing were made using a K-type thermocouple (RS Components UK), either mounted alone for calibration measurements or attached to the films while undergoing sonication.

2.4.2. Study of Structural Changes. Ultraviolet-visible (UV-vis) spectrometry was performed with a Zeiss, MCS 522 UV VIS spectrometer, and the films were removed periodically from the systems described above to record the UV-vis spectra.

${ }^{1} \mathrm{H}$ NMR spectroscopy analysis was carried out on a Bruker $500 \mathrm{MHz}$ spectrometer using tetramethylsilane as the internal reference and deuterated dimethyl sulfoxide as the solvent.

\section{RESULTS AND DISCUSSION}

3.1. Isomerization Using UV and Visible Light and Ultrasound. The compositions of the polymers used in this investigation are shown in Table 1; a broader table of characteristics are shown in Table $\mathrm{S} 1$, and the $\mathrm{AB}$ loading in each polymer was established by ${ }^{1} \mathrm{H}$ NMR.

A typical trace of the $\mathrm{t}-\mathrm{AB} \rightarrow \mathrm{c}-\mathrm{AB}$ isomerization in a $20 \%$ mol $\mathrm{P}(\mathrm{MMA} / \mathrm{MOAB})$ thin film exposed to UV radiation at 25 ${ }^{\circ} \mathrm{C}$ is given in Figure 3a. The spectrum has two distinct absorption bands: $318 \mathrm{~nm}$ which is attributed to the trans isomers due to the $\pi-\pi^{*}$ transition state and $440 \mathrm{~nm}$ corresponding to the cis isomers due to the forbidden $n-\pi^{*}$ transition. ${ }^{25}$ The absorbance band at $318 \mathrm{~nm}$ sharply decreases and the weak band at $440 \mathrm{~nm}$ increases after UV irradiation. Complete $\mathrm{t}-\mathrm{AB} \rightarrow \mathrm{c}-\mathrm{AB}$ isomerization is accomplished after $300 \mathrm{~s}$.

Figure $3 \mathrm{~b}$ presents the $\mathrm{c}-\mathrm{AB} \rightarrow \mathrm{t}-\mathrm{AB}$ isomerization of the same film under the same conditions but under exposure to visible light. The trans band at $318 \mathrm{~nm}$ increases noticeably after visible irradiation and the cis band at $440 \mathrm{~nm}$ decreases 
Table 1. AB Concentration of the Polymeric Films and Their Rate Constant Values for Cis $\rightarrow$ Trans Isomerization of $\mathrm{AB}$ in Polymeric Films

\begin{tabular}{lcc}
\multicolumn{1}{c}{ names } & $\mathrm{AB}$ concentration $(\% \mathrm{~mol})$ & $k\left(\mathrm{~h}^{-1}\right)$ \\
0\% PMMA & 0 & \\
10\% P(MMA/MOAB $)$ & 10.9 & 0.708 \\
20\% P(MMA/MOAB $)$ & 19.0 & 0.738 \\
30\% P(MMA/MOAB $)$ & 30.8 & 0.582 \\
45\% P(MMA/MOAB $)$ & 44.4 & 0.960 \\
65\% P(MMA/MOAB $)$ & 61.0 & 1.068 \\
80\% P(MMA/MOAB $)$ & 84.0 & 1.140 \\
100\% PMOAB & 100 & 1.056 \\
\hline
\end{tabular}

with irradiation time. Complete $\mathrm{c}-\mathrm{AB} \rightarrow \mathrm{t}-\mathrm{AB}$ isomerization of $\mathrm{AB}$ in the polymers is accomplished after $30 \mathrm{~s}$ of exposure to visible light. The rate of $c-A B \rightarrow t-A B$ conversion is expected to be faster than the $\mathrm{t}-\mathrm{AB} \rightarrow \mathrm{c}-\mathrm{AB}$ conversion because the trans form is thermodynamically more favorable $\left(\sim 55 \mathrm{~kJ} \mathrm{~mol}^{-1}\right.$ energy difference $\Delta H_{\mathrm{f}}($ cis $)=367 \mathrm{~kJ} \mathrm{~mol}^{-1}, \Delta H_{\mathrm{f}}($ trans $)=312$ $\mathrm{kJ} \mathrm{mol}^{-1}$ ) than the cis form, and thus the overall reaction rate is dominated by the trans isomeric direction.

The effect of ultrasound on the isomerization in this film can be seen in Figure 3c. As with treatment by visible light, the intensity of the $318 \mathrm{~nm}$ trans peak increases with sonication time and the intensity of the $440 \mathrm{~nm}$ cis peak decreases, showing that switching of $\mathrm{c}-\mathrm{AB} \rightarrow \mathrm{t}-\mathrm{AB}$ occurs in the solid films when exposed to ultrasound. Complete recovery of the cis isomers to the trans conformation in a $20 \% \mathrm{~mol} \mathrm{AB}$ copolymer is achieved within $7200 \mathrm{~s}$, which is significantly longer than the recovery time by visible light (30 s). Similar recovery behaviors were observed in all polymer films containing different $\mathrm{AB}$ loadings, and the results are shown in Table 1 .

The conversion rate to the trans form by visible light is much faster $(30-60 \mathrm{~s})$ than by sonication (7200-9000 s) because visible irradiation stimulates only the $c-A B \rightarrow t-A B$ isomerization, whereas sonication can trigger both $t-A B \rightarrow c-$ $\mathrm{AB}$ and $\mathrm{c}-\mathrm{AB} \rightarrow \mathrm{t}-\mathrm{AB}$ isomerization reactions. ${ }^{15}$

Ultrasound and photo-induced isomerization in the copolymer films were further confirmed by ${ }^{1} \mathrm{H}$ NMR spectroscopy. The ${ }^{1} \mathrm{H}$ NMR spectra of the pretreated film (Figure $4 \mathrm{a}$ ) shows three broad signals for the protons of the benzene ring of the trans $\mathrm{AB}$ pendant: $\delta 7.87-8.05(4 \mathrm{H}), \delta$ $7.48-7.62(3 \mathrm{H})$, and $\delta 7.20-7.43(2 \mathrm{H})$ ppm. Additional

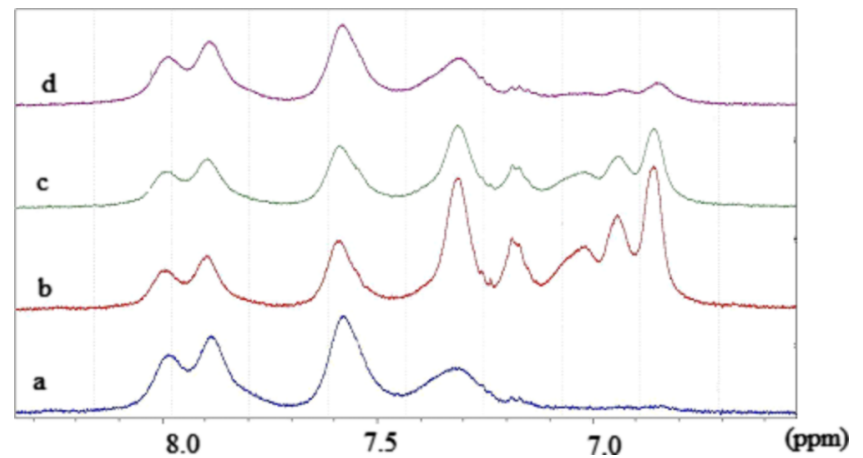

Figure 4. ${ }^{1} \mathrm{H}$ NMR spectra of the $10 \% \mathrm{P}(\mathrm{MMA} / \mathrm{MOAB})$ film. (a) Untreated sample (97.4\% trans and $2.6 \%$ cis), (b) UV irradiated $(23.7 \%$ trans and $76.3 \% \mathrm{cis})$, (c) 60 min sonication (48.3\% trans and $51.7 \%$ cis), and (d) 120 min sonication (90.5\% trans and 9.5\% cis).

signals at $\delta 6.75-7.20 \mathrm{ppm}$ (Figure $4 \mathrm{~b}$ ), attributed to the aromatic protons from the cis configuration of $\mathrm{AB}$ in the polymeric chain, ${ }^{26}$ appeared after $10 \mathrm{~min}$ of UV irradiation, whereas the intensity of the signals due to trans isomers decreased indicating $\mathrm{t}-\mathrm{AB} \rightarrow \mathrm{c}-\mathrm{AB}$ isomerization of the $\mathrm{AB}$ chromophores.

When the UV-treated film with cis conformation was exposed to ultrasound waves for $60 \mathrm{~min}$, the intensity of the chemical shifts at $\delta 6.75-7.20 \mathrm{ppm}$ (Figure 4c) decreased to $48.3 \%$, which is attributed to $\mathrm{c}-\mathrm{AB} \rightarrow \mathrm{t}-\mathrm{AB}$ isomerization. Further treatment of this film with ultrasound demonstrated $91 \%$ recovery of the trans isomers within $120 \mathrm{~min}$, as seen in Figure $3 \mathrm{~d}$. The UV-vis and ${ }^{1} \mathrm{H}$ NMR spectroscopic results are in good agreement, confirming that ultrasound can trigger the $c-A B \rightarrow t-A B$ isomerization of polymer thin films when $A B$ chromophores are in the side chains. Whereas the NMR measurements are in solution rather than in the solid state, they give a strong measure of confidence that the data given in Figure 3 is meaningful and that conformational changes in the loaded polymeric systems are occurring.

A comparison of the time required for complete $\mathrm{c}-\mathrm{AB} \rightarrow \mathrm{t}$ $\mathrm{AB}$ conversion (Supporting Information Figure $\mathrm{S} 1$ ) after exposure to ultrasound waves and visible light shows that all $\mathrm{P}(\mathrm{MMA} / \mathrm{MOAB})$ compositions achieve the same total conversion, suggesting that the $\mathrm{AB}$ concentration plays no significant role in the mechanism of $\mathrm{c}-\mathrm{AB} \rightarrow \mathrm{t}-\mathrm{AB}$ isomerization. There is some variation of rate constant with composition (Table 1), implying that the kinetics of the

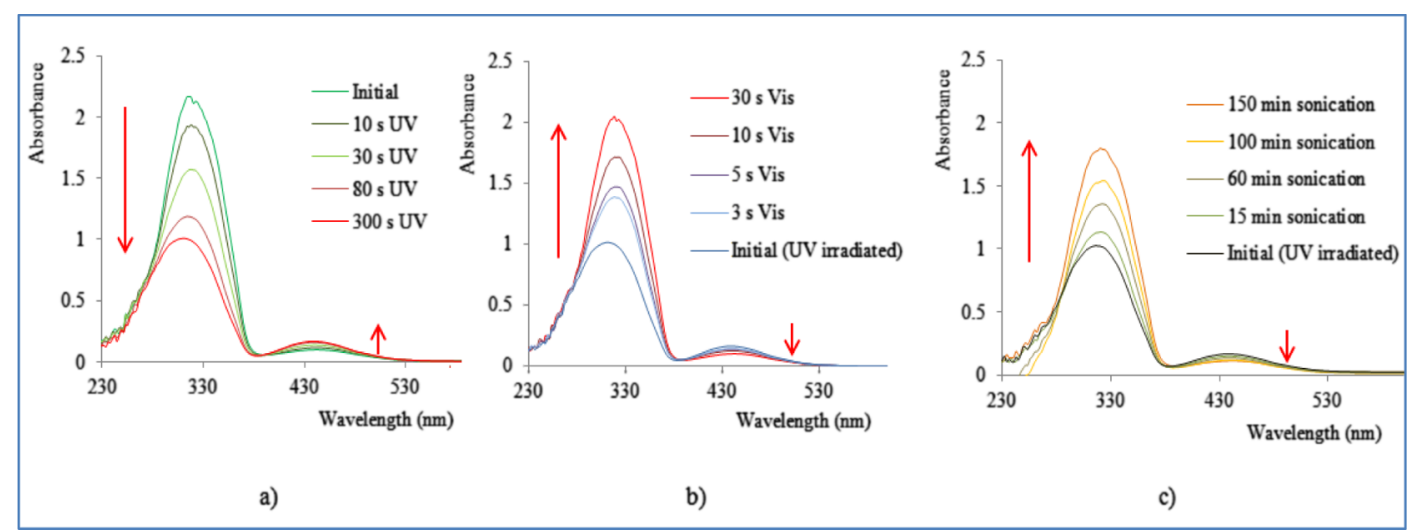

Figure 3. UV-vis spectra of the $20 \% \mathrm{P}(\mathrm{MMA} / \mathrm{MOAB}$ ) film after (a) UV irradiation, (b) visible irradiation, and (c) exposure to ultrasound waves and increase/decrease direction of individual peaks. 
process change but not the underlying mechanism. This general trend for higher rate constants with increased $A B$ loading can be attributed to steric hindrance occurring during the polymer transformation, simply slowing the process down; however, the possibility of entropic chain stretching of the network may be another factor.

3.2. Effects of Ultrasound. The quantum yield of $t-A B \rightarrow$ $c-A B$ is not substantially altered by temperature but approaches zero at about $110 \mathrm{~K}$ for $\mathrm{c}-\mathrm{AB} \rightarrow \mathrm{t}-\mathrm{AB}$ isomerization. This indicates a strong dependence of thermal vibrations ${ }^{15}$ leading to an expectation that ultrasound will increase the temperature of the $\mathrm{AB}$-containing films during sonication. Initial tests showed that a $20 \% \mathrm{~mol} \mathrm{P}(\mathrm{MMA} / \mathrm{MOAB})$ thin film at $25^{\circ} \mathrm{C}$, which completes $\mathrm{c}-\mathrm{AB} \rightarrow \mathrm{t}-\mathrm{AB}$ isomerization within $7200 \mathrm{~s}$, is subject to appreciable heat during ultrasound treatment.

To observe the ultrasound-induced heating of the sample, the temperature of the ultrasonic bath was continuously monitored during ultrasound treatment. A typical heating curve of the bath temperature during ultrasonic treatment is shown in Figure 5. This shows that when the bath temperature

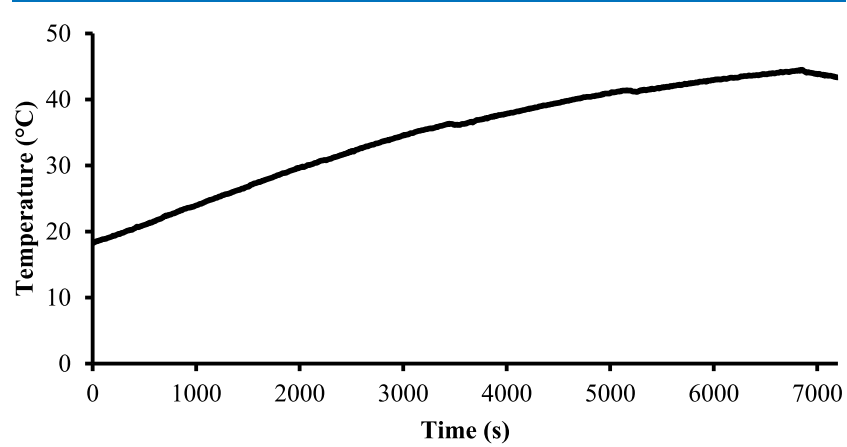

Figure 5. Thermal heating for a bath at room temperature undergoing sonication.

is held at $20{ }^{\circ} \mathrm{C}$, there was an increase in the temperature of the bath by approximately $20^{\circ} \mathrm{C}$ within $\sim 120 \mathrm{~min}$. Aligned to this is a calibration of the effects of heat on $c-A B \rightarrow t-A B$ conversion, without the input of ultrasound.

Individual samples were placed in the heating bath and removed at appropriate temperatures, and then the absorbance was immediately measured for the given temperature. This gives a measure of the thermal contribution for any specific temperature, effectively a "background" removal.

This value can then be subtracted from the values of absorbance generated by ultrasound at that given temperature, giving a value of both the thermal and ultrasonic components of conversion. The temperature-time plot in Figure 5 is important, as the heating ramp is not linear.

Figure 6 shows the amount of cis isomers that was reverted to the trans counterparts in a $20 \% \mathrm{~mol} \mathrm{P}(\mathrm{MMA} / \mathrm{MOAB})$ thin film by heating in a bath at the described rate from 20 to $40{ }^{\circ} \mathrm{C}$ and also by ultrasonic treatment of this film contained in a bath at $20{ }^{\circ} \mathrm{C}$.

It clearly shows that at every measured temperature, the level of $\mathrm{c}-\mathrm{AB} \rightarrow \mathrm{t}-\mathrm{AB}$ conversion is greater for the sonically treated films compared to those that are simply heat-treated. This means that the conversion of $c-A B \rightarrow t-A B$ is caused by the interaction of ultrasound with the polymeric film, not just from the associated temperature rise due to sonication of the surrounding media. The difference at low temperatures between the sonicated and heated samples is ascribed to the

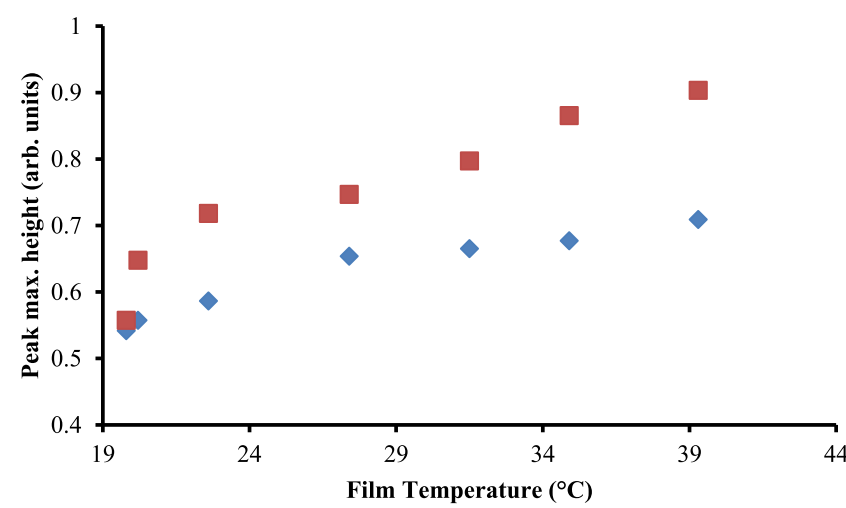

Figure 6. Cis-to-trans conversion of $20 \% \mathrm{P}(\mathrm{MMA} / \mathrm{MOAB})$ thin films after exposure to heat (blue diamond) and sonication (brown square).

faster effect of the sonication than the more gradual heating effect.

Not only is the total amount of $c-A B \rightarrow t-A B$ conversion greater for sonication rather than pure heating, the rate of conversion is also greater in the sonically treated films. The temperature profile for the purely heated system is effectively linear across the heating range, whereas for the ultrasonically treated films, the linearity occurs after $\sim 23{ }^{\circ} \mathrm{C}$. The behavior at lower temperatures of the ultrasonically treated films can be readily explained by the different modes by which the heating occurs; in the purely heated system, the temperature is wellcontrolled by the surrounding heat sink environment; in the ultrasonic case, it is caused by the (unthermostated) ultrasonic agitation, thus when initiated, the system takes a little time to settle down into a steady state, which it does shortly after the ultrasonic treatment begins.

An initial GPC of untreated samples shows that $8 \%$ of the material is in the trans form. This can then be assigned to the initial UV-vis spectra peak height. By purely heating a sample and then removing it at specific times/temperature (as defined by the curve in Figure 4) and measuring the associated cis-totrans isomerism, the contribution given by pure heating can be established. Repeating this for the samples undergoing sonication and calculating the difference in peak heights allow the contribution of sonication to be established (Figure S2).

Using this as a calibration and examining the amounts of converted $\mathrm{c}-\mathrm{AB} \rightarrow \mathrm{t}-\mathrm{AB}$ forms, we estimate that the heating effect causes $\sim 46 \%$ of the conversion and that pure ultrasonic agitation causes $\sim 46 \%$ of the reverse isomerization for the total isomerization. The remaining $8 \%$ remained in the trans form. Sonication must have an effect upon the polymer outside that of heating and most likely is due to the sonic treatment upon the amorphous polymer itself, causing changes in the isomerization state. If it were purely due to the heating effect on the surrounding liquid, then such a disparity in the amounts transformed would not have been observed. Although the heating and sonication contributions are approximately equal, this is simply an attribute of this material, and we would expect other materials to have different contributions.

This finding is at variance with the findings of Surampudi et al. $^{20}$ who reported a $100 \%$ recovery of $\mathrm{c}-\mathrm{AB} \rightarrow \mathrm{t}-\mathrm{AB}$ isomer in an $\mathrm{AB}$ polymer solution by ultrasound treatment. However, Surampudi et al did not exclude possible heating effects because of expected temperature rises of the solution during ultrasound treatment, and the current study is examining both 
a different system and the one that is in the solid state, rather than a solution. In the solution state, any generated heat can be more easily dissipated in the enveloping media, whereas in the solid state, the heat loss will be primarily due to conductive processes, which in general will occur much more slowly for an organic solid-there is as yet no definitive data for the thermal conductivity or heat capacity for these $\mathrm{AB}$-based polymeric films, although bulk PMMA has a thermal heat conductivity of $\sim 0.19 \mathrm{~W} \mathrm{~m}^{-1} \mathrm{~K}^{-1}$. $^{27}$

PMMA is an amorphous polymer, and it is well-established that the thermal properties of such systems are anisotropic with the randomness of the polymer chains limiting the phonon free path within the system. ${ }^{28}$ However, imposing an external structure on the polymer will then affect the thermal properties, whether that is a fiber where thermal parameters along the fiber axis are well-understood but radial thermal parameters are $\operatorname{not}^{29}$ or as in this case, where a thin film is employed leading to a two-dimensional character. In addition, these initial differences due to structure are then enhanced by the internal changes brought about by the isomerization processes and may play a part in the fatigue of these systems.

Our findings show that $\mathrm{c}-\mathrm{AB} \rightarrow \mathrm{t}-\mathrm{AB}$ isomerization in solid polymer films can be triggered ultrasonically, but it increases the temperature of the sample, which can enhance both $c-A B$ $\rightarrow \mathrm{t}-\mathrm{AB}$ and $\mathrm{t}-\mathrm{AB} \rightarrow \mathrm{c}-\mathrm{AB}$. This finding suggests that the cis isomer calculated from NMR spectroscopy analysis in Figure 4 is overestimated because both heating effects were excluded from the results and they examine solution, rather than the solid forms.

3.3. Pseudokinetics of Isomerization. In an attempt to better define the kinetics of the system, the absorbance values at $318 \mathrm{~nm}$ collected in an isothermal manner were examined (a typical trace being given in Figure 3c). The kinetics of change in intensity was modelled by eq $1^{20}$

$$
k_{t}=\ln \frac{\left(A_{\infty}-A_{t}\right)}{\left(A_{\infty}-A_{0}\right)}
$$

where $A_{\infty}$ is the absorbance of the film at time $150 \mathrm{~min}, A_{0}$ is the initial absorbance, and $A_{t}$ is the absorbance value at time $t$. Typical plots of $\ln \left(A_{\infty}-A_{t}\right) /\left(A_{\infty}-A_{0}\right)$ as a function of ultrasonic treatment time for $20 \% \mathrm{P}(\mathrm{MMA} / \mathrm{MOAB})$ at various temperatures are given in Figure $\mathrm{S} 3 \mathrm{a}-\mathrm{d}$ in the Supporting Information. Of the four temperature runs, it is clear that those performed at 25 and $50{ }^{\circ} \mathrm{C}$ have two distinct gradient regions, the first slope passing through zero and the second slope not passing through zero. This indicates that the initial process is a first-order process, but is followed later by a process that is not a first-order process. For the runs at 35 and $40{ }^{\circ} \mathrm{C}$, there appears to be only one process, which is first order. The firstorder rate constants derived range from 0.03 to $1.10 \mathrm{~h}^{-1}$, (dependent upon the temperature) which compare favorably to previous reports ${ }^{11}$ of 0.61 and $0.91 \mathrm{~h}^{-1}$ for this class of polymer in a THF solution. The rate constants for 25 and 50 ${ }^{\circ} \mathrm{C}$, which are not first order, lie between 0.01 and $0.16 \mathrm{~h}^{-1}$, which are lower than those previously cited but within the same order of magnitude; so most likely reflect simple mechanistic changes rather than major ones or they may possibly reflect the pseudoisothermal nature of the data.

The activation energy of this process was calculated from the Arrhenius plot, as shown in Figure S4, and is found to be 111(1) $\mathrm{kJ} \mathrm{mol}^{-1}$, which lies very close to the data cited by Bandara and Burdette, who reported the activation energy for the $\mathrm{AB}$ chromophore $\mathrm{c}-\mathrm{AB} \rightarrow \mathrm{t}-\mathrm{AB}$ isomerization in solution ${ }^{15}$ to be $95 \mathrm{~kJ} \mathrm{~mol}^{-1}$, for the melt to be $105 \mathrm{~kJ} \mathrm{~mol}^{-1}$, and for crystalline materials to be $233 \mathrm{~kJ} \mathrm{~mol}^{-1}$.

Although this value appears reasonable, it must be approached with a modicum of suspicion. As noted in a previous section, although these runs were made in the isothermal mode, the ultrasonic agitation does cause heating, and hence these data are not isothermal. However, given that the logarithmic plots do show a strong degree of linearity, the data suggest that it is a useful estimation to give. With the temperature calibration included (and a worst case heating scenario in place), this increases to $\sim 126 \mathrm{~kJ} \mathrm{~mol}^{-1}$ for the polymer system. This suggests that whatever the exact temperature, the thermal barriers to reorganization in this polymeric system do not particularly hinder the mechanism(s) that occurs and that thermal barriers to switching are not enhanced by $\mathrm{AB}$ chromophores being restricted by the physical cross-links in the polymers. The smaller rate of reaction of $\mathrm{t}-\mathrm{AB}$ $\rightarrow \mathrm{c}-\mathrm{AB}$ isomerization in the solid polymer film is attributed to the restricted conformational changes in the rigid polymer matrix. It is common that a change in the structures and matrices can change the rate of isomerization by stimuli such as light and dark. ${ }^{30}$ The impact of structural features of $A B$ derivatives on cis-to-trans isomerization kinetics was reported by Bujak et al. The authors found dark-return cis-to-trans isomer to be twice as faster for azopyridine derivatives than for their $\mathrm{AB}$ analogues.

\section{CONCLUSIONS}

It has been shown that ultrasonic agitation of the $\mathrm{P}(\mathrm{MMA} /$ $M O A B)$ solid thin films does trigger $c-A B \rightarrow t-A B$ isomer confirmation, and after discounting the thermal isomerization effect, the isomerization due to pure ultrasound could be observed to be about $46 \%$ in $2 \mathrm{~h}$, with $46 \%$ being contributed by ultrasound-induced thermal excitation, the remainder being untransformed trans isomers. It may appear to be a philosophical question whether solid-state transitions are purely induced by ultrasound or by the thermal response to ultrasound, but it is important to be able to define the two components as they do have different impacts. Clearly pure ultrasound can wholly convert cis-to-trans conformations (at least in solution ${ }^{20}$ ) and thermal effects can also drive the counter trans-to-cis switch, which, if not understood and quantified, can lead to problems in further work or applications.

In demonstrating the ultrasound-induced switching of cis $\mathrm{AB}$ isomers to their trans counterparts in solid polymer films, it is clear that the incorporation of the $\mathrm{AB}$ chromophore does not affect the thermal barriers to conformational change. However, within a more complex solid structure, this hinders the capacity for physical reorganization required for switching such molecular structures, say compared to solution-based systems, and leads to slower interconversion. Although this decrease in the switching time can be a problem (if fast switching times are required), it can also clearly be a benefit if slow times are necessary, for example, in stimuli-responsive drug-delivery systems $^{31}$ and protein immobilization. ${ }^{32}$

This work advances our understanding of the vibrationinduced isomerization and indicates where material functions, such as fatigue behavior of AB-based materials, can and do occur when used for various applications such as opticalmechanical devices, solar thermal energy storage, and reversible data storage. 
Studies to further define the properties of these materials are ongoing, for example, to fully understand the influence of strength and frequency of ultrasound on the behavior of these materials, developing mechanical and analytical methods to study fatigue processes, and truly defining isothermal conditions to permit a more consistent and coherent measure of the activation energy of transformation and, of course, to develop new materials with enhanced properties.

\section{ASSOCIATED CONTENT}

\section{S Supporting Information}

The Supporting Information is available free of charge on the ACS Publications website at DOI: 10.1021/acsomega.8b02048.

Polymer thermal and weight characteristics, relationship between exposure time and $\mathrm{AB}$ concentration, cis-trans isomerization plot, pseudokinetic plots of isomerization, and Arrhenius plot (PDF)

\section{AUTHOR INFORMATION}

\section{Corresponding Author}

*E-mail: m.moniruzzaman@cranfield.ac.uk.

\section{ORCID $\odot$}

Mohammed Moniruzzaman: 0000-0002-9953-8120

Ranko M. Vrcelj: 0000-0001-6327-2300

Philip P. Gill: 0000-0001-8811-8342

Notes

The authors declare no competing financial interest.

\section{ACKNOWLEDGMENTS}

The authors would like to thank Dr Guillaume Kister for his advice during the execution of this work and acknowledge the Defence Science and Technology Laboratory (DSTL) for funding the work.

\section{REFERENCES}

(1) Kondo, M.; Miyasato, R.; Naka, Y.; Mamiya, J.-i.; Kinoshita, M.; Yu, Y.; Barrett, C. J.; Ikeda, T. Photomechanical properties of azobenzene liquid-crystalline elastomers. Liq. Cryst. 2009, 36, 12891293.

(2) Kondo, M.; Sugimoto, M.; Yamada, M.; Naka, Y.; Mamiya, J.-i.; Kinoshita, M.; Shishido, A.; Yu, Y.; Ikeda, T. Effect of concentration of photoactive chromophores on photomechanical properties of crosslinked azobenzene liquid-crystalline polymers. J. Mater. Chem. 2010, 20, 117-122.

(3) Liu, Z. F.; Hashimoto, K.; Fujishima, A. Photoelectrochemical information storage using an azobenzene derivative. Nature 1990, 347, 658-660.

(4) Natansohn, A.; Rochon, P. Photoinduced Motions in AzoContaining Polymers. Chem. Rev. 2002, 102, 4139-4176.

(5) Yu, H.; Iyoda, T.; Ikeda, T. Photoinduced Alignment of Nanocylinders by Supramolecular Cooperative Motions. J. Am. Chem. Soc. 2006, 128, 11010-11011.

(6) Ikeda, T.; Tsutsumi, O. Optical switching and image storage by means of azobenzene liquid-crystal films. Science 1995, 268, 18731875.

(7) Hugel, T.; Holland, N. B.; Cattani, A.; Moroder, L.; Seitz, M.; Gaub, H. E. Single-Molecule Optomechanical Cycle. Science 2002, 296, 1103-1106.

(8) Banerjee, I. A.; Yu, L.; Matsui, H. Application of Host-Guest Chemistry in Nanotube-Based Device Fabrication: Photochemically Controlled Immobilization of Azobenzene Nanotubes on Patterned $\alpha$-CD Monolayer/Au Substrates via Molecular Recognition. J. Am. Chem. Soc. 2003, 125, 9542-9543.
(9) Yamada, M.; Kondo, M.; Mamiya, J.-i.; Yu, Y.; Kinoshita, M.; Barrett, C. J.; Ikeda, T. Photomobile Polymer Materials: Towards Light-Driven Plastic Motors. Angew. Chem., Int. Ed. 2008, 47, 49864988.

(10) Isayama, J.; Nagano, S.; Seki, T. Phototriggered Mass Migrating Motions in Liquid Crystalline Azobenzene Polymer Films with Systematically Varied Thermal Properties. Macromolecules 2010, 43, 4105-4112.

(11) Bai, Y.; Hu, J.; Shen, W.; Hu, X. Recent advances and potential applications of the photo-induced macroscopic response of selfassembled azopolymer in aqueous media. Polym. Int. 2014, 63, 15391544.

(12) Pathem, B. K.; Zheng, Y. B.; Payton, J. L.; Song, T.-B.; Yu, B.C.; Tour, J. M.; Yang, Y.; Jensen, L.; Weiss, P. S. Effect of Tether Conductivity on the Efficiency of Photoisomerization of AzobenzeneFunctionalized Molecules on $\mathrm{Au}\{111\}$. J. Phys. Chem. Lett. 2012, 3, 2388-2394.

(13) Suda, M.; Nakagawa, M.; Iyoda, T.; Einaga, Y. Reversible Photoswitching of Ferromagnetic FePt Nanoparticles at Room Temperature. J. Am. Chem. Soc. 2007, 129, 5538-5543.

(14) Emoto, A.; Uchida, E.; Fukuda, T. Optical and Physical Applications of Photocontrollable Materials: Azobenzene-Containing and Liquid Crystalline Polymers. Polymers 2012, 4, 150-186.

(15) Bandara, H. M. D.; Burdette, S. C. Photoisomerization in different classes of azobenzene. Chem. Soc. Rev. 2012, 41, 1809-1825.

(16) Yager, K. G.; Barrett, C. J. Smart Light Responsive Materials: Azobenzene Containing Polymers and Liquid Crystals, 1st ed.; Zhao, Y., Ikeda, T., Eds.; Wiley: New Jersey, 2009; p 15.

(17) Moniruzzaman, M.; Zioupos, P.; Fernando, G. F. Investigation of reversible photo-mechanical properties of azobenzene-based polymer films by nanoindentation. Scr. Mater. 2006, 54, 257-261.

(18) Richter, A.; Nowicki, M.; Wolf, B. A Nanoindentation Study of Photo-Induced Changes in Polymers Containing Azobenzene. Molecul. Cryst. Liq. Cryst. 2008, 483, 49-61.

(19) Christogianni, P.; Moniruzzaman, M.; Kister, G. Light-triggered enhancement of mechanical properties and healing effect in azobenzene-based polymer films. Polymer 2015, 77, 272-277.

(20) Surampudi, S. K.; Patel, H. R.; Nagarjuna, G.; Venkataraman, D. Mechano-isomerization of azobenzene. Chem. Commun. 2013, 49, 7519-7521.

(21) Ishitobi, H.; Nakamura, I.; Kobayashi, T.-a.; Hayazawa, N.; Sekkat, Z.; Kawata, S.; Inouye, Y. Nanomovement of Azo Polymers Induced by Longitudinal Fields. ACS Photonics 2014, 1, 190-197.

(22) Plain, J.; Wiederrecht, G. P.; Gray, S. K.; Royer, P.; Bachelot, R. Multiscale Optical Imaging of Complex Fields Based on the Use of Azobenzene Nanomotors. J. Phys. Chem. Lett. 2013, 4, 2124-2132.

(23) Durgun, E.; Grossman, J. C. Photoswitchable Molecular Rings for Solar-Thermal Energy Storage. J. Phys. Chem. Lett. 2013, 4, 854860 .

(24) Hu, X.; Zhao, X.; Gan, L. H.; Xia, X. Synthesis, characterization, and photochromic properties of PMMA functionalized with 4,4?diacryloyloxyazobenzene. J. Appl. Polym. Sci. 2002, 83, 1061-1068.

(25) Briquet, L.; Vercauteren, D. P.; André, J.-M.; Perpète, E. A.; Jacquemin, D. On the geometries and UV/Vis spectra of substituted trans -azobenzenes. Chem. Phys. Lett. 2007, 435, 257-262.

(26) Moniruzzaman, M.; Talbot, J. D. R.; Sabey, C. J.; Fernando, G. F. The use of ${ }^{1} \mathrm{H}$ NMR and UV-Vis measurements for quantitative determination of trans/cis isomerization of a photo-responsive monomer and its copolymer. J. Appl. Polym. Sci. 2006, 100, 11031112.

(27) Hsieh, W.-P.; Losego, M. D.; Braun, P. V.; Shenogin, S.; Keblinski, P.; Cahill, D. G. Testing the minimum thermal conductivity model for amorphous polymers using high pressure. Phys. Rev. B: Condens. Matter Mater. Phys. 2011, 83, 174205.

(28) Choy, C. L. Thermal conductivity of polymers. Polymer 1977, 18, 984-1004.

(29) Lu, Y.; Liu, J.; Xie, X.; Cahill, D. G. Thermal Conductivity in the Radial Direction of Deformed Polymer Fibers. ACS Macro Lett. 2016, 5, 646-650. 
(30) Bujak, K.; Orlikowska, H.; Małecki, J. G.; Schab-Balcerzak, E.; Bartkiewicz, S.; Bogucki, J.; Sobolewska, A.; Konieczkowska, J. Fast dark cis-trans isomerization of azopyridine derivatives in comparison to their azobenzene analogues: Experimental and computational study. Dyes Pigm. 2019, 160, 654-662.

(31) Gulzar, A.; Gai, S.; Yang, P.; Li, C.; Ansari, M. B.; Lin, J. Stimuli responsive drug delivery application of polymer and silica in biomedicine. J. Mater. Chem. B 2015, 3, 8599-8622.

(32) Eom, T.; Yoo, W.; Kim, S.; Khan, A. Biologically activatable azobenzene polymers targeted at drug delivery and imaging applications. Biomaterials 2018, 185, 333-347. 